\title{
Medicinal cannabis
}

\section{Bridin Murnion}

Senior staff specialist Drug Health Services Royal Prince Alfred Hospital

Clinical senior lecturer Addiction Medicine Faculty of Medicine University of Sydney Sydney

\section{Key words}

cannabidiol, drug

regulation, medical

marijuana, nabiximols

Aust Prescr 2015;38:212-5

\section{SUMMARY}

A number of therapeutic uses of cannabis and its derivatives have been postulated from preclinical investigations.

Possible clinical indications include spasticity and pain in multiple sclerosis, cancer-associated nausea and vomiting, cancer pain and HIV neuropathy. However, evidence is limited, may reflect subjective rather than objective outcomes, and is not conclusive.

Controversies lie in how to produce, supply and administer cannabinoid products. Introduction of cannabinoids therapeutically should be supported by a regulatory and educational framework that minimises the risk of harm to patients and the community. The Regulator of Medicinal Cannabis Bill 2014 is under consideration in Australia to address this.

Nabiximols is the only cannabinoid on the Australian Register of Therapeutic Goods at present, although cannabidiol has been recommended for inclusion in Schedule 4.

\section{Introduction}

The intoxicating properties of cannabis have been recognised for millennia. The major psychoactive constituent of cannabis is $\triangle$-9-tetrahydrocannabinol (THC). The non-psychoactive cannabidiol is another major component. Characterisation of these and other derivatives, as well as the receptors they interact with, has increased our understanding of the endocannabinoid system.

Evidence from animal studies has supported a role for cannabis derivatives and endocannabinoids in acute, visceral and cancer pain, neuro-inflammatory and neurodegenerative disorders, appetite and weight gain, cancer, seizure disorder and inflammatory bowel disease. ${ }^{2}$ This has led to clinical studies of cannabis.

It is imperative that debate around medicinal cannabis use is not confused with legalisation of recreational marijuana.

\section{Cannabis products}

There is no agreed definition of medicinal cannabis. The term is used to refer to the therapeutic use of herbal cannabis and its constituents. Nabiximols is the only medicinal cannabis included on the Australian Register of Therapeutic Goods (ARTG). It is a combination of cannabidiol and THC in a spray, indicated for muscle relaxation for spasticity in multiple sclerosis. Nabiximols is a Schedule 8 drug. Cannabidiol has been recommended for inclusion in Schedule $4{ }^{3}$

Nabiximols is also available overseas along with other cannabis products including:4

- nabilone - a synthetic derivative of THC

- dronabinol-synthetic THC
- cannabidiol

- oral cannabis extract

- herbal medicinal cannabis with defined amounts of cannabidiol and THC

- unregulated cannabis.

In the Netherlands, the Office for Medicinal Cannabis oversees production of pharmaceutical grade herbal cannabis. Different strains of cannabis are cultivated under stringent conditions with strict quality control to produce herbal cannabis with variable but

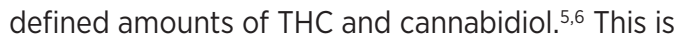
distributed through pharmacies and is supported by patient information. ${ }^{5}$

\section{Pharmacology of THC and cannabidiol}

The most studied cannabinoids are THC and cannabidiol. THC is the major psychoactive constituent of cannabis and acts as a partial agonist at $\mathrm{CB} 1$ and $\mathrm{CB} 2$ receptors. ${ }^{7}$ Cannabidiol is not psychoactive and is an antagonist at CB1 and CB2. ${ }^{8}$ It acts at multiple other receptors and can be an agonist in some systems.

Cannabidiol reduces the psychoactive effect of THC, improving its tolerability and, perhaps also, its safety by reducing the likelihood of adverse psychiatric effects. Cannabis also contains other less well characterised phytocannabinoids. Metabolites of parent compounds may also have activity. ${ }^{7,9}$

\section{The endocannabinoid system}

The endocannabinoid system is complex and has numerous physiological roles including 
immunomodulation, neuroplasticity, learning, emotional modulation, motivation, appetite, vascular function and gut motility. ${ }^{10}$

The cannabinoid receptors - CB1 and CB2 - are predominantly inhibitory. ${ }^{9,10} \mathrm{CB} 1$ is mainly located in the central and peripheral nervous systems, altering neurotransmitter release, and CB2 on immune cells, modifying cytokine release.

\section{Animal models of disease}

A role for cannabinoid receptor modulation has been suggested in a number of diseases. ${ }^{2,7}$ In animal studies, CB1 receptor activation reduced nausea and vomiting, and increased feeding. It also reduced seizures and nociception in visceral pain. Reduction of intraocular pressure has also been demonstrated. Activation of the $\mathrm{CB} 1$ receptor may enhance survival in haemorrhagic and cardiogenic shock.

Animal studies have also shown that activation of $\mathrm{CB} 1$ and $\mathrm{CB} 2$ receptors may reduce the clinical manifestations of multiple sclerosis, neuropathic and inflammatory pain, and reduce tumour cell growth and angiogenesis in some cancers. CB2 receptor activation reduces inflammation and progression of atherosclerosis, and increases apoptosis. ${ }^{2}$

\section{Clinical applications}

Cannabis has been trialled for various indications.

\section{Multiple sclerosis}

The American Academy of Neurology has developed a consensus statement on the use of cannabinoids for multiple sclerosis. Evidence supports oral cannabis extract, THC and nabiximols for subjective, but not objective, improvements in spasticity. Oral cannabis extract reduces central pain in multiple sclerosis, while THC and nabiximols are probably effective. The efficacy of smoked cannabis in either spasticity or central pain is unclear."

\section{HIV}

A modest benefit of dronabinol has been shown in HIV-associated weight loss. However, robust data in patients receiving highly active antiretroviral therapy are not available. ${ }^{12}$ In HIV neuropathy, smoked cannabis reduces pain, including experimentally induced pain, when assessed by changes in visual analogue scores. ${ }^{13}$

\section{Chronic non-cancer pain}

While cannabis and derivatives show some efficacy in pain associated with multiple sclerosis, cancer and HIV, evidence in other painful conditions is inconclusive. In patients with rheumatoid arthritis, there may be a minor effect on pain. ${ }^{13}$ Evidence for efficacy of cannabinoids in fibromyalgia is limited. ${ }^{13}$
Overall, medicinal cannabis is not recommended in chronic non-cancer pain. Indeed its psychoactive effects may cause poor engagement in multimodal, non-pharmacological pain management. ${ }^{14}$

\section{Cancer}

The US National Cancer Institute reports evidence for the use of nabiximols, nabilone and cannabis in cancerrelated pain. ${ }^{15}$ Cancer Council Australia's position statement similarly acknowledges some benefit in pain, appetite stimulation and nausea. ${ }^{16}$ Nabilone and dronabinol are approved in Europe and the USA for cancer-related vomiting. There is not adequate evidence for inhaled cannabis in this indication. ${ }^{15}$

\section{Epilepsy}

There are mixed data in animal models of epilepsy. THC has been shown to be both pro- and anticonvulsant. Cannabidiol appears more promising, with some limited experience in humans. ${ }^{17}$ Preliminary data from a trial of cannabidiol (Epidiolex) found benefit in treatment-resistant paediatric epilepsy. ${ }^{18}$ This has led to much community debate, and to parents accessing cannabinoids illegally for treatment of children with catastrophic epilepsy syndromes. ${ }^{19}$

\section{Cannabis withdrawal}

Recent data show that nabiximols reduces symptoms during cannabis withdrawal, but does not impact on long-term outcomes. ${ }^{20}$

\section{Neurodegenerative disorders}

The antioxidant and anti-inflammatory properties of cannabidiol have led to investigation of cannabinoids in neurodegenerative disorders including Huntington's disease, Parkinson's disease and neonatal hypoxiaischaemia. No definitive role has been identified. ${ }^{8}$

\section{Appetite suppression}

Rimonabant, a CB1 receptor inverse agonist*, was available briefly for appetite suppression. However, it was withdrawn due to psychiatric adverse effects. ${ }^{21}$

\section{Toxicities}

The psychoactive effects of cannabis include anxiety, dysphoria, euphoria, hallucinations, paranoia, acute memory impairment and reduced cognitive performance. Acute cannabis use is also associated with increased motor vehicle accidents. ${ }^{22}$

Increased airway diseases and oropharyngeal cancers may be risks of smoking cannabis. Other chronic toxicities include dependence, increased risk of schizophrenia and, probably, cognitive impairment. ${ }^{22}$

\footnotetext{
* An inverse agonist binds to a receptor but has the opposite effect of an agonist.
} 
In clinical trials, discontinuations because of adverse effects were predominantly in response to psychiatric events. These were associated with higher doses of THC," and were less common at higher doses of cannabidiol. ${ }^{5}$ Notably, in a number of American states where medical cannabis laws have been enacted, there is a reduction in overdose deaths from opioids. ${ }^{23}$

\section{Challenges}

There are many challenges in considering medicinal cannabis. ${ }^{24}$ Evidence supports the use of medicinal cannabis in a small number of conditions, but there is significant community pressure for use beyond these conditions.

The complexity of endocannabinoid signalling and the multiple receptor targets of cannabinoids present challenges when developing compounds with predictable efficacy and toxicity. ${ }^{8,25}$ Ideally, medicines are provided as refined molecules with defined pharmacology, accurate dosing, minimal adverse effects and optimal efficacy. However, it may be that therapeutic benefits are effected by the mixture of compounds in herbal cannabis, rather than by the isolated cannabinoid.

Diversion of medicinal cannabis is of concern, as is early initiation of use in adolescents. There is also the risk of accidental childhood overdose. ${ }^{24}$

Canadian guidelines for cannabis 'prescribing' recognise that treatment with herbal cannabis is not a prescription per se, and suggest various methods for improving safety. ${ }^{26,27}$

As in all therapeutic decisions, the principles of the quality use of medicines should be followed. These include considering if a medicine is needed and, if so, choosing one that is safe and effective in the correct formulation and dose. ${ }^{28}$

In general, smoking herbal cannabis is not recommended. Vaporising or ingestion of herbal product is purportedly safer, but dosing remains inaccurate and bioavailability variable., ${ }^{4,5}$
A harm-benefit assessment is critical in decision making. In terminal disease or intractable epilepsy, using products or delivery routes that might otherwise be unacceptable may be supported.

\section{Regulation}

Legislation around medicinal cannabis is complex and evolving. Products listed on the ARTG are governed by the Therapeutic Goods Act 1989. ${ }^{29}$ The Narcotic Drugs Act 1967 regulates narcotic cultivation and production. ${ }^{30}$ The Regulator of Medicinal Cannabis Bill 2014 is currently under consideration by the Australian Government. ${ }^{31}$ This bill, if enacted, would provide a system for regulating cannabis independent of the Therapeutic Goods Administration, and a system for cannabis cultivation and production parallel to the Narcotic Drugs Act. ${ }^{31}$ Development of such a regulatory system will likely be costly.

If medicinal cannabis is to be introduced, it should be supported with prescriber and consumer education, prescriber peer review, a robust authority process and pharmacovigilance for adverse events. Hopefully we can prevent the emergence of the problems seen with prescription opioids and benzodiazepines. The regulatory framework must be responsive to changes in evidenced-based practice.

\section{Conclusion}

There is some evidence of therapeutic benefit for cannabis products in defined patient populations. While waiting for a regulatory framework, more defined products, and more definitive data to become available, a major question is whether herbal cannabis should be introduced, with appropriate legislation to prevent criminalisation, for strictly defined populations and diseases. Monitoring for individual and community safety should be a component of any model. $<$

Conflict of interest: none declared

\section{REFERENCES}

1. Skaper SD, Di Marzo V. Endocannabinoids in nervous system health and disease: the big picture in a nutshell. Philos Trans R Soc Lond B Biol Sci 2012;367:3193-200.

2. Pertwee RG. Targeting the endocannabinoid system with cannabinoid receptor agonists: pharmacological strategies and therapeutic possibilities. Philos Trans R Soc Lond B Biol Sci 2012;367:3353-63.

3. Therapeutic Goods Administration. Reasons for the medicines scheduling delegates final decisions, March 2015 (Medicines). Advisory Committee on Medicines Scheduling meeting, 18 November 2014. Canberra: Australian Government Department of Health; 2015.

www.tga.gov.au/book/part-final-decisions-matters-referredexpert-advisory-committee-2 [cited 2015 Nov 4]

4. Mather LE, Rauwendaal ER, Moxham-Hall VL, Wodak AD. $(\mathrm{Re})$ introducing medicinal cannabis. Med J Aust 2013;199:759-61.

5. Brunt TM, van Genugten M, Höner-Snoeken K van de Velde MJ, Niesink RJ. Therapeutic satisfaction and subjective effects of different strains of pharmaceuticalgrade cannabis. J Clin Psychopharmacol 2014;34:344-9.

6. Office for Medicinal Cannabis. The Hague: Netherlands Ministry of Health, Welfare and Sport; 2015. www.cannabisbureau.nl/English [cited 2015 Nov 4]

7. Pertwee $\mathrm{RG}$. The diverse $\mathrm{CB} 1$ and $\mathrm{CB} 2$ receptor pharmacology of three plant cannabinoids: delta9tetrahydrocannabinol, cannabidiol and delta9tetrahydrocannabivarin. Br J Pharmacol 2008;153:199-215.

8. Fernández-Ruiz J, Sagredo O, Pazos MR, García C, Pertwee R, Mechoulam R, et al. Cannabidiol for neurodegenerative disorders: important new clinical applications for this phytocannabinoid? $\mathrm{Br} \mathrm{J}$ Clin Pharmacol 2013;75:323-33. 
9. Pertwee RG, Howlett AC, Abood ME, Alexander SP, Di Marzo V, Elphick MR, et al. International Union of Basic and Clinical Pharmacology. LXXIX. Cannabinoid receptors and their ligands: beyond $\mathrm{CB}_{1}$ and $\mathrm{CB}_{2}$. Pharmacol Rev 2010;62:588-631.

10. Rodríguez de Fonseca F, Del Arco I, Bermudez-Silva FJ, Bilbao A, Cippitelli A, Navarro M. The endocannabinoid system: physiology and pharmacology. Alcohol Alcohol 2005;40:2-14

11. Koppel BS, Brust JC, Fife T, Bronstein J, Youssof S, Gronseth G, et al. Systematic review: efficacy and safety of medical marijuana in selected neurologic disorders: report of the Guideline Development Subcommittee of the American Academy of Neurology. Neurology 2014;82:1556-63.

12. Lutge EE, Gray A, Siegfried N. The medical use of cannabis for reducing morbidity and mortality in patients with HIV/AIDS. Cochrane Database Syst Rev 2013;4:CD005175.

13. Lynch ME, Campbell F. Cannabinoids for treatment of chronic non-cancer pain; a systematic review of randomized trials. Br J Clin Pharmacol 2011;72:735-44.

14. Faculty of Pain Medicine. Statement on 'Medicinal Cannabis' with particular reference to its use in the management of patients with chronic non-cancer pain. Melbourne: Australian and New Zealand College of Anaesthetists; 2015

15. National Cancer Institute. Cannabis and cannabinoids for health professionals (PDQ). Bethesda (MD): National Institutes of Health; 2015.

www.cancer.gov/about-cancer/treatment/cam/hp/cannabispdq [cited 2015 Nov 4]

16. Cancer Council Australia. Medical use of cannabis: a joint position statement with the Clinical Oncology Society of Australia. Sydney: Cancer Council Australia; 2014 http://wiki.cancer.org.au/policy/Position_statement_Medical_use of cannabis [cited 2015 Nov 4]

17. Devinsky O, Cilio MR, Cross H, Fernandez-Ruiz J, French J, Hill C, et al. Cannabidiol: pharmacology and potentia therapeutic role in epilepsy and other neuropsychiatric disorders. Epilepsia 2014;55:791-802.

18. Devinsky O, Sullivan J, Friedman D, Thiele E, Marsh E, Laux L, et al. Abstract 3.303. Efficacy and safety of Epidiolex (cannabidiol) in children and young adults with treatmentresistant epilepsy: initial data from an expanded access program. Chicago (IL): American Epilepsy Society; 2014. www.aesnet.org/meetings_events/annual_meeting_ abstracts/view/1868751 [cited 2015 Nov 4

19. Smethurst A. Desperate parents turn to medical marijuana in last-ditch effort to improve their children's lives. Melbourne: Herald Sun [online edition]; 2014 Jan 12.

www.heraldsun com.au/news/victoria/desperate-parentsturn-to-medical-marijuana-in-lastditch-effort-to-improvetheir-childrens-lives/story-fniOfit3-1226799787147 [cited 2015 Nov 4]
20. Allsop DJ, Copeland J, Lintzeris N, Dunlop AJ, Montebello M, Sadler $\mathrm{C}$, et al. Nabiximols as an agonist replacement therapy during cannabis withdrawal: a randomized clinical trial. JAMA Psychiatry 2014;71:281-91.

21. Public Statement on Acomplia (rimonabant): withdrawal of the marketing authorisation in the European Union. London: European Medicines Agency; 2009 Jan 30.

22. Hall W, Degenhardt L. Adverse health effects of non-medical cannabis use. Lancet 2009;374:1383-91.

23. Bachhuber MA, Saloner B, Cunningham CO, Barry CL. Medical cannabis laws and opioid analgesic overdose mortality in the United States, 1999-2010. JAMA Intern Med 2014;174:1668-73.

24. Bulletin series 18: The use of cannabis for medical purposes. Sydney: National Cannabis Prevention and Information Centre; 2014 Sep. https://ncpic.org.au/professionals/publications/bulletins/ the-use-of-cannabis-for-medical-purposes/ [cited 2015 Nov 4 ]

25. Pacher P, Kunos G. Modulating the endocannabinoid system in human health and disease--successes and failures. FEBS 2013;280:1918-43.

26. Canadian Medical Protection Association. Medical marijuana: New regulations, new College guidance for Canadian doctors. Ottawa: CMPA; 2015 July.

https://www.cmpa-acpm.ca/en/legal-and-regulatoryproceedings/-/asset_publisher/a9unChEc2NP9/content/ medical-marijuana-new-regulations-new-college-guidancefor-canadian-doctors [cited 2015 Nov 4]

27. Kahan M, Srivastava A, Spithoff S, Bromley L. Prescribing smoked cannabis for chronic noncancer pain: preliminary recommendations. Can Fam Physician 2014;60:1083-90.

28. Pharmaceutical Health And Rational use of Medicines (PHARM) Committee. The National Strategy for Quality Use of Medicines. Canberra: Australian Government Department of Health; 2002.

29. Therapeutic Goods Administration. Legislation and legislative instruments. Canberra: Australian Government Department of Health; 2015.

www.tga.gov.au/legislation-legislative-instruments [cited 2015 Nov 4]

30. Narcotic Drugs Act 1967, Comp. No. 9. (Jul 1, 2015).

31. Regulator of Medicinal Cannabis Bill 2014, Senate, Parl No. 44. (Nov 27, 2014)

\section{NPS \\ MEDICINEWISE PROFESSIONAL}

\section{Free Clinical e-Audit for GPs}

\section{Chronic pain: opioids and beyond}

Navigate your way through chronic pain management using a multimodal approach.

- Earn 40 (Category 1) RACGP QI\&CPD points (QI activity)

- Earn 30 ACRRM PRPD points

- Recognised for the Practice Incentives Program Quality Prescribing Incentive (PIP QPI)

Find out more and enrol at nps.org.au/chronic-pain-clinical-audit

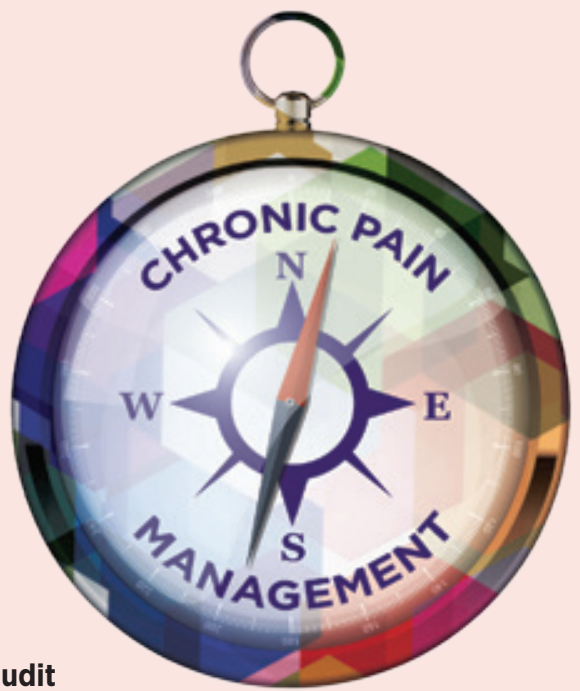

